\title{
Gas Turbine Performance Enhancement for Naval Ship Propulsion using Wave Rotors
}

\author{
Dr. Antonios Fatsis, Deputy Head, Marine Engineering Department \\ Military Technological College, \\ Muscat, Sultanate of Oman \\ Antonios.Fatsis@mtc.edu.om \\ Eng. Abdullah Said Najman Al Balushi, Head, Marine Engineering Department \\ Military Technological College, \\ Muscat, Sultanate of Oman \\ AbdullahS.Albalushi@mtc.edu.om
}

\section{Synopsis}

The propulsion demands of high speed naval vessels often rely on gas turbines fitted in small engine rooms, producing significant amounts of power achieving thus high performance requirements. Gas turbines can be used either to provide purely mechanical propulsion, or alternatively to generate electricity, which is subsequently used by electric drives to propel the ship. However, the thermal efficiencies of gas turbines are lower than those of Diesel engines of similar power, in addition to the fact that all gas turbines are less efficient as the ambient temperature rises, particularly for aero-derivative engines. In the context of improving the performance of existing marine gas turbines with minimum modifications to their baseline configuration, this article is proposing engine's performance enhancement by integrating a pressure wave supercharger (or wave rotor), while keeping the compressor, combustion chamber and turbine entry temperature of the baseline engine unchanged.

Thermodynamic cycle analysis for two-shaft gas turbine engines configurations with and without heat exchanger to recuperate the waste heat from the exhaust gases, typical for marine propulsion is performed for the baseline engines, as well as for the topped with four-port wave rotor engines, at design point conditions and their performances are compared accordingly. Important benefits are obtained for four-port wave rotor-topped engines in comparison to the self-standing baseline engines for the whole range of engine's operation. It is found that the higher the turbine inlet temperature is, the more the benefit gain of the wave rotor topped engine is attained in terms of efficiency and specific power. It is also concluded that the integration of wave rotor particularly favours engines operating at low compressor pressure ratios and high turbine inlet temperatures. The effect of variation of the most important parameters on performance of the topped engine is investigated. It is concluded that wave rotor topping of marine gas turbines can lead to fuel savings and power increase.

Keywords - wave rotor, marine gas turbine, thermal efficiency, specific power, recuperator

\section{Introduction}

During the last forty years most of Western Navies have begun to utilize aero-derivative gas turbine engines as prime movers for surface combatants due to enhanced performances that could not be attained with diesel engines, Brady (1988). Although the naval community had attempted the use of this type of engines for ship propulsion, it was only after a successful commercial campaign during the 70s that gas turbines were used for naval propulsion systems. Today, the use of aircraft derivative engines has certain advantages such as reduced manning, maintenance and weight, short warm-up times, ease of control, low $\mathrm{NO}_{\mathrm{X}}$ and negligible $\mathrm{SO}_{\mathrm{X}}$ emissions due to higher grades of fuel and therefore reduced cost, Kayadelen and Üst (2013). Current world navy maritime practice includes a variety of gas turbines for propulsion and electric power. The aim of using combination of different propulsion configurations, such as gas turbines with diesel engines and electric drive units, is the optimization of system design in order to minimize fuel consumption and maximize 
operating flexibility and reliability. The main disadvantages of gas turbines are related to high fuel consumption which combined to the price of the fuel for aero-derivative gas turbines which is currently expensive with respect to conventional marine fuel, makes the operation of gas turbines costly. According to the Royal Academy of Engineering (2013), the efficiency of gas turbines drops as the ambient temperature rises, and thermal efficiencies of gas turbines are lower than those of diesel engines of similar power. This is the reason why several methods have been adopted to improve the efficiency of gas turbines for naval use. The most popular of those applied in marine gas turbines is the ICR (Intercooled Recuperated) cycle where a recuperator (or regenerator) is added after the low pressure compressor, prior to the combustion chamber of the intercooled cycle to recover waste exhaust heat and heat up the compressed air. Shepard et al. (1994) concluded that the ICR cycle leads to efficiency increase of the baseline engine.

An alternative method for efficiency improvement and at the same time power increase is the integration of a pressure wave exchanger or wave rotor to marine gas turbines. A wave rotor consists of a purely cylindrical rotor inside a casing. The rotor is composed of two coaxial cylinders. Circumferentially equidistant axial straight blades are formed between these cylinders. Two stationary endwall plates with perforated circumferential openings are mounted at the rotor extremities, allowing only partial inflow and outflow through the rotor blade channels, as described by Weber (1996) and Povinelli et al. (2000). Depending of the number of openings (or ports), wave rotors can be classified as three-port, four-port or five-port configurations. In figure 1, one can see the four-port wave rotor assembly, which is the configuration best suited as a gas turbine topping device, Wilson and Paxson, (1993).

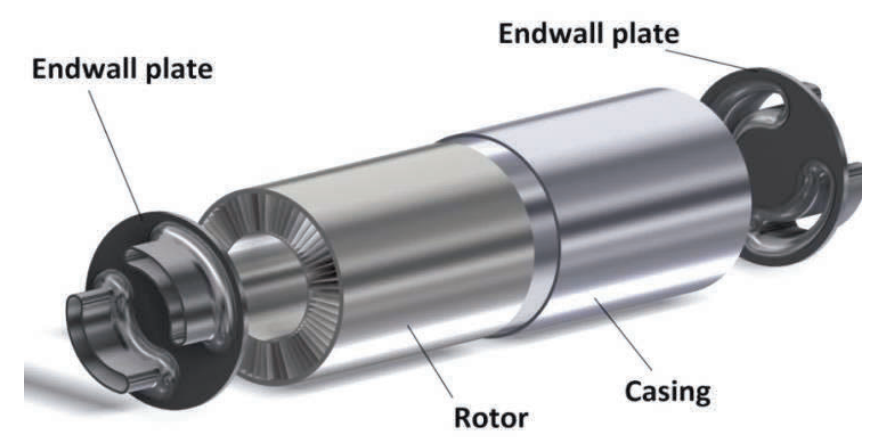

Figure 1: Four-port wave rotor schematic configuration the baseline engine. Unlike conventional turbomachinery components, the principle of operation of wave rotors is based on propagation of unsteady pressure waves inside the various rotor channels. These moving pressure waves are formed inside the wave rotor channels when a high enthalpy gas stream (e.g. hot combustion gas) is coming in contact for a short time -so that mixing is avoided- with low enthalpy gas (e.g. compressed air) being inside the rotor. According to the basic theory of gas dynamics described by Weber (1996) and verified analytically and numerically by Iancu and Müller (2005), the propagation of a compression wave inside each of the rotor channels results to the formation of an expansion wave and its propagation at the opposite direction. The contact discontinuity between the high and the low enthalpy gas streams guarantees that no mixing between the two streams will occur. When a wave rotor is integrated in a gas turbine, extra compression in the air flow is achieved by means of compression waves formed inside the wave rotor channels when hot exhaust gases coming out of the combustion chamber come in contact with air from the compressor. Simultaneously expansion is achieved when expansion waves are directed at the outflow port towards the turbine. An efficient design of wave rotors is attained when the pressure waves inside the rotor result in uniform and steady flows at the outflow ports, so that the air flow towards the combustion chamber and the gas flow towards the turbine are uniform. For the case of the four-port through flow wave rotor, the rotor blades are self-cooled because hot gas and compressed air are traversing the rotor, so no extra cooling is needed.

Feasibility studies of integrating a wave rotor to aircraft gas turbines showed reduction of the specific fuel consumption and increase of the specific thrust delivered by the engine, as stated by Jones and Welch (1996). A recent publication by Fatsis (2019) explored the possibility of integrating a four-port wave rotor also to industrial gas turbines.

This article is an original study on wave rotor technology applied to marine gas turbines used for naval propulsion. Performance assessment is performed for two-shaft gas turbines with and without recupertor at design point conditions by means of the thermodynamics model developed. The most important parameters of the wave rotor topped engines are identified and their variations around standard values listed in the literature indicate the effect on engine's performance. 


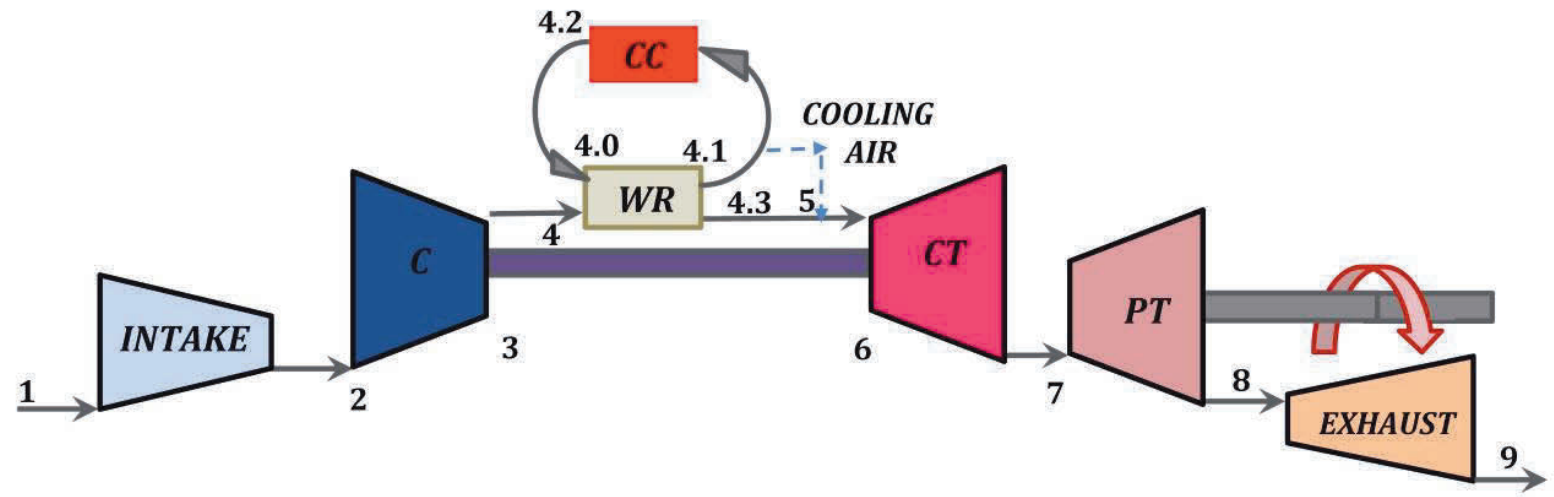

Figure 2: Two-shaft gas turbine configuration, C: compressor, T: turbine, CC: combustion chamber, WR: wave rotor, CT: compressor turbine, PT: power turbine

It is concluded that integration of wave a rotor to a marine gas turbine improves the thermal efficiency of the engine and at the same time increases its specific power. The improvement is more remarkable for engines operating with low compressor pressure ratios and high Turbine Inlet Temperatures, for the range of compressor pressure ratios examined.

\section{Gas turbine Thermodynamic Calculations}

\subsection{Input data for two-shaft gas turbines}

The procedure of the thermodynamic calculations of one and two-shaft gas turbine cycles with the integration of a four-port wave rotor is described in detail by Fatsis (2018). It is based on standard thermodynamic analysis of gas turbines, as presented by Horlock (2003) and by Razak (2007), adding the compression and expansion processes inside the wave rotor. Figure 2 illustrates the configurations for the wave rotor-topped two-shaft gas turbines used in this article.

The thermodynamic properties of combustion gases and air at various stages throughout the gas turbine cycle are calculated by considering variation of temperature according to Ebaid and Al-hamdan, (2015). In the equations below $T_{a}$ and $T_{g}$ are the average temperatures during the compression and expansion processes in the compressor and turbine respectively.

For air at low temperature range of 200 to $800 \mathrm{~K}$

$C_{P a}=1.0189 \times 10^{3}-0.13784 T_{a}+1.9843 \times 10^{-4} T_{a}^{2}+$ $4.2399 \times 10^{-7} T_{a}{ }^{3}-3.7632 \times 10^{-10} T_{a}^{4}$
For air at high temperature range of 800 to $2200 \mathrm{~K}$

$C_{P a}=7.9865 \times 10^{2}+0.5339 T_{a}-2.2882 \times 10^{-4} T_{a}^{2}+$ $3.7421 \times 10^{-8} T_{a}^{3}$

For specific heats of products of combustion

$$
C_{P g}=C_{P a}+(f /(1+f)) B_{T}
$$

where $B_{T}$ at low temperature range of 200 to $800 \mathrm{~K}$ is given by:

$B_{T}=-3.59494 \times 10^{2}+4.5164 T_{g}+2.8116 \times 10^{-3} T_{g}{ }^{2}-$ $2.1709 \times 10^{-5} \mathrm{~T}_{g}^{3}+2.8689 \times 10^{-8} \mathrm{Tg}^{4}-1.226 \times 10^{-11} \mathrm{Tg}^{5}$

and $B_{T}$ at high temperature range of 800 to $2200 \mathrm{~K}$ is given by:

$$
\begin{aligned}
& B_{T}=1.0888 \times 10^{3}-0.1416 T_{g}+1.916 \times 10^{-3} T_{g}{ }^{2} \\
& -1.2401 \times 10^{-6} T_{g}{ }^{3}+3.0669 \times 10^{-10} T_{g}{ }^{-}- \\
& 206117 \times 10^{-14} T_{g}{ }^{5}
\end{aligned}
$$

Constant values are assumed for the air and for the exhaust gases as: $\gamma_{c}=1.4$ and $\gamma_{h}=1.333$. Table 1 summarizes typical values of input data used Inlet Temperature, (TIT) and the compressor pressure $\operatorname{ratio}\left(r_{c}\right)$. 


\begin{tabular}{|c|c|c|}
\hline Quantity & $\begin{array}{c}\text { Symbol, } \\
\text { Unit }\end{array}$ & Value \\
\hline Ambient pressure & $P_{a}, k P a$ & 101.3 \\
\hline Ambient temperature & $T_{a}, K$ & 288 \\
\hline Intake pressure losses & $\Delta P_{i n}(\%)$ & 1 \\
\hline Compressor pressure ratio & $r_{c}$ & $5 \div 30$ \\
\hline $\begin{array}{c}\text { Combustion chamber } \\
\text { pressure losses }\end{array}$ & $\Delta P_{c c}(\%)$ & 5 \\
\hline $\begin{array}{c}\text { Fuel Low Calorific Value } \\
\text { Turbine Inlet } \\
\text { Temperature }\end{array}$ & $T I T, \mathrm{KJ} / \mathrm{K} g$ & 42.8 \\
\hline $\begin{array}{c}\text { Isentropic compressor } \\
\text { efficiency }\end{array}$ & $\eta_{i s c}$ & $1000 \div$ \\
\hline $\begin{array}{c}\text { Combustion chamber } \\
\text { efficiency }\end{array}$ & $\eta_{c c}$ & 0.99 \\
\hline $\begin{array}{c}\text { Isentropic turbine } \\
\text { efficiency }\end{array}$ & $\eta_{i s t}$ & 0.90 \\
\hline
\end{tabular}

Table 1: Baseline Engine typical Input Data

\subsection{Input data for wave rotor}

Typical input data for wave rotor thermodynamic calculations are summarized in Table 2 . The wave rotor parameters chosen to be varied are the wave rotor pressure ratio, $\mathrm{PR}$, the ducting and leakage losses $\left(\Delta P_{\text {duct }}\right)$ and compression and expansion efficiencies, $\eta_{\mathrm{C}}, \eta_{\mathrm{E}}$.

\begin{tabular}{|c|l|c|}
\hline $\begin{array}{c}\text { Symbol, } \\
\text { Unit }\end{array}$ & \multicolumn{1}{|c|}{ Quantity } & Value \\
\hline$P R$ & Wave rotor pressure ratio & $1.4 \div 2.2$ \\
\hline$\Delta P_{\text {duct }}(\%)$ & Ducting and leakage losses & $8 \div 16$ \\
\hline$n_{C}$ & $\begin{array}{l}\text { Efficiency of compression } \\
\text { processes inside the wave } \\
\text { rotor }\end{array}$ \\
\hline$n_{E}$ & $\begin{array}{l}\text { Efficiency of expansion } \\
\text { processes inside the wave } \\
\text { rotor }\end{array}$ \\
\hline
\end{tabular}

Table 2: Wave Rotor Typical Input Data

Figure 3 illustrates the model developed to calculate the thermodynamic properties of air and hot gases when a four-port wave rotor is integrated to a two-shaft gas turbine. The four-port configuration has been proposed by many researchers, e.g. Jones and Welch (1996), Povinelli et al. (2000), Fatsis (2018), as the most promising one to be integrated to an existing gas turbine, because it can easily be connected to compressor, combustion chamber and turbine of the engine.

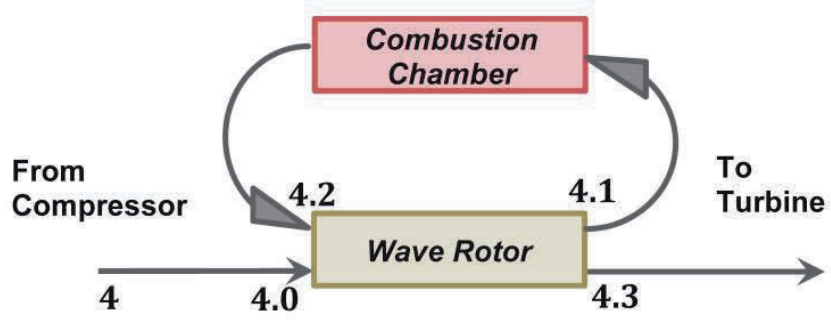

Figure 3: Symbols used for the four-port wave rotor thermodynamic calculations

In the four-port configuration, schematically shown in figure 3 , when the hot exhaust gases from the combustion chamber exit enter the wave rotor from the "hot" port 4.2, they come in contact with the compressed air from the compressor which is already inside the rotor through the "cold" port 4.0 and has filled the space between the rotor blades. These two streams (i.e. the "cold" air and the "hot" exhaust gases) are brought into contact inside the rotor. As a result, a compression wave is initiated and the air stream it further compressed; the compression wave is propagating along the rotor, reflected on solid walls directed via the port 4.1 towards the combustion chamber. Simultaneously, an expansion wave is formed due to the contact of the streams of "cold" air and the "hot" gases. It is propagating to the opposite direction (with respect to the compression wave), reflected on solid walls directed towards the turbine through the port 4.3. The location of the inlet and outlet ports of the rotor depends on the unsteady wave interaction inside the rotor (called wave diagram) and its rotational speed, which is about one third the rotational speed of the high pressure turbine shaft. Okamoto (2004) presents in detail the wave diagram inside four port wave rotors, by means of analytical and numerical calculations.

The wave rotor pressure ratio is a very important parameter that characterizes the performance of the wave rotor and accordingly the performance of the whole gas turbine. It is defined as:

$$
P R=\frac{P_{4.1}}{P_{4.0}}
$$

This parameter gives the extra compression inside the wave rotor of the air flow stream exiting the gas turbine compressor.

Stagnation temperature at the cold air port of the wave rotor, $T_{4.0}$

$T_{4.0}=T_{04}$

Stagnation temperature at the port towards the turbine, $T_{4.3}$ 
$T_{4.3}=T I T$

Stagnation pressure at the cold air port of the wave rotor $P_{4.0}$

$$
P_{4.0}=P_{04}\left(1-\frac{\Delta P_{\text {duct }}}{100}\right)
$$

where the term $\Delta P_{\text {duct }}$ includes the pressure losses at the ducts connecting the wave rotor to compressor, combustion chamber and turbine and the leakage losses occurring between the rotating part (rotor) and the stationary openings (ports) of the wave rotor.

Stagnation temperature at the wave rotor exit towards the combustion chamber, $T_{4.1}$ is obtained by using isentropic efficiency of the compression process inside the wave rotor.

$T_{4.1}=T_{4.0} \cdot\left(\frac{P R^{\left(\gamma_{c}-1\right) / \gamma_{c}}-1}{\eta_{C}}+1\right)$

where $\eta_{C}$ is the compression efficiency inside the wave rotor.

Stagnation pressure at the combustion chamber outlet $P_{4.2}$

$$
P_{4.2}=P_{4.1}\left(1-\frac{\Delta P_{c c}}{100}\right)
$$

where the term $\Delta P_{c c}$ represents the pressure losses in the combustion chamber.

Stagnation temperature at the combustion chamber exit, $T_{4.2}$ is obtained by using isentropic efficiency of the expansion process inside the wave rotor.

$$
T_{4.2}=\frac{T_{4.3}}{1-\left[1-\left(\frac{P_{4.3}}{P_{4.2}}\right)^{\left(\gamma_{h}-1\right) / \gamma_{h}}\right] \cdot n_{E}}
$$

where $\eta_{E}$ is the expansion efficiency inside the wave rotor.

The pressure at the wave rotor outflow towards the turbine is given according to Wilson and Paxson (1993) by:

$P_{4.3}=P_{4.0} \cdot P R\left\{\frac{1-\frac{C_{p a}\left(1-n_{E}\right)}{C_{p h} n_{E} n_{C}} \cdot \frac{T_{04}}{T I T} \cdot\left(P R^{\frac{\gamma_{c}-1}{\gamma_{c}}}-1\right)}{1+\frac{C_{p a}}{C_{p h} n_{E}} \cdot \frac{T_{04}}{T I T} \cdot\left(P R^{\frac{\gamma_{c}-1}{\gamma_{c}}}-1\right)}\right\}^{\frac{\gamma_{h}}{\gamma_{h}-1}}$
The above relation is known in the literature (Wilson and Paxson, 1993) as the characteristic of the wave rotor.

\subsection{Performance}

Power consumed by the compressor, $\dot{W}_{C}$

$\dot{W}_{C}=\dot{m}_{a i r} \cdot C_{p c} \cdot\left(T_{03}-T_{02}\right)$

Power produced by the turbine $\dot{W}_{T}$ is used to drive the compressor

$\dot{W}_{T}=\dot{W}_{C}$

Heat added by the fuel $\dot{Q}_{i n}$

$\dot{Q}_{\text {in }}=\dot{m}_{f} \cdot F C V$

Power produced by the power turbine, $\dot{W}_{P T}$

$\dot{W}_{P T}=\left(\dot{m}_{\text {air }}+\dot{m}_{f}\right) \cdot C_{p h} \cdot\left(T_{07}-T_{08}\right)$

Net power delivered by the engine, $\dot{W}_{N}$

$\dot{W}_{N}=\dot{W}_{P T}$

Specific power ws

$w s=\frac{\dot{W}_{N}}{\dot{m}_{\text {air }}}$

Thermal efficiency $\eta_{t h}$

$\eta_{t h}=\frac{\dot{W}_{N}}{\dot{Q}_{I N}}$

Specific fuel consumption, $s f c$

$s f c=\frac{1}{\eta_{t h} \cdot F C V}$ 


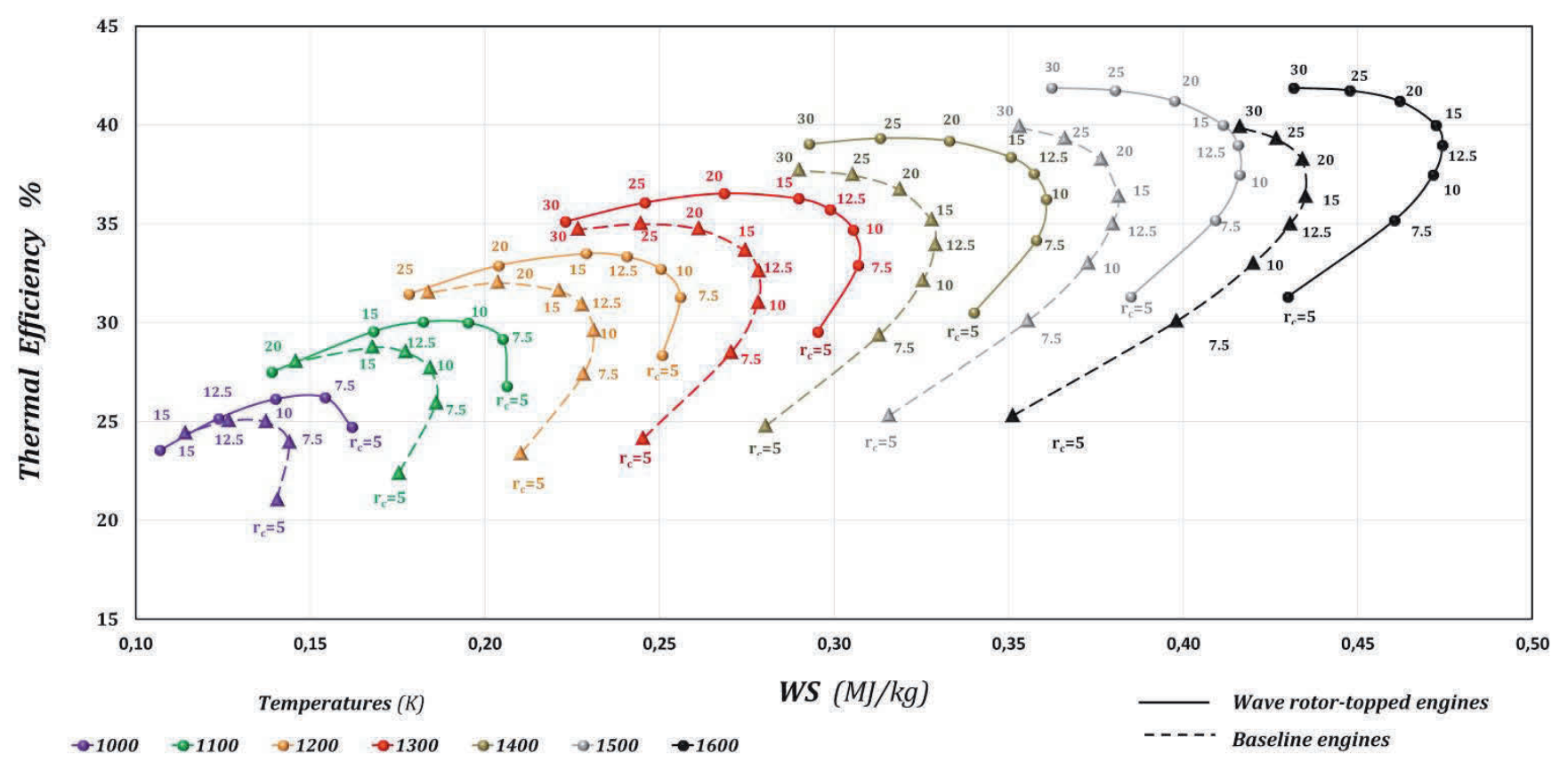

Figure 4: Thermal efficiency percentage against specific power for baseline and wave rotor-topped twoshaft gas turbines

The allowable temperature of metal used to manufacture the blades is approximately 800 - 900 ${ }^{\circ} \mathrm{C}$, but the allowable surface temperature of blades has been increased up to $1000{ }^{\circ} \mathrm{C}$ due to the recent application of thermal barrier coatings on blade surfaces, Moon et al. (2018). Thus, in the simulations, the surface temperature of the blades is set to be constant at $1000{ }^{\circ} \mathrm{C}$. The present thermodynamic model accounts for cooling the turbine in case $T I T \geq 1300 \mathrm{~K}$ by subtracting air flow from the high pressure outflow port of the wave rotor. The coolant flow rate is determined by considering various operating parameters such as the operating temperature of the blades and the temperatures and specific heats of the main gas and coolant. The coolant flow rate at the design point is calculated using an energy balance equation based on the inlet air flow rate, power output, efficiency, gas turbine outlet temperature, and TIT according to the method proposed by Moon et al. (2018). Similar methods in the literature are according to Prasad et al. (2016) and to Jonsson et al. (2005). Turbine blades are made of nickel or rhenium alloys capable of withstanding high heat without distortion. The High Pressure Turbine airfoils as well as the Power Turbine airfoils are cooled. They are made of INCO 738 coated with a silicon aluminide coating, (Shepard et al., 1994).

\section{Wave Rotor two-shaft Gas Turbines analysis}

3.1 Thermal efficiency, specific power and specific fuel consumption at design point of twoshaft gas turbines.

Figure 4 presents the performance curves of wave rotor topped two-shaft gas turbines at design point for various values of $r_{c}$ and TIT, illustrated with continuous lines in comparison to the base line (without wave rotor) two-shaft gas turbines illustrated with dotted lines. These results correspond to $P R=1.8$ and $n_{E}=n_{C}=0.83$. Dotted lines with triangular symbols illustrate the performance of the baseline engines while continuous lines with spherical symbols of the same color illustrate the performance of the wave rotor-topped engines. specific two-shaft gas turbine. Each symbol in the diagram corresponds to the design point conditions of a specific twoshaft gas turbine. From this figure, it can be seen that for a given value of turbine inlet temperature, thermal efficiency of wave-rotor topped engines, as well as specific power are increasing with respect to their values of the base line engines. As it is easily seen, the performance curves of the wave rotor-topped engines are shifted to the upper right part of the diagram. Figure 5 presents the $s f c-w s$ distribution of wave rotor topped two-shaft gas turbines at design point conditions for various values of $r_{c}$ and TIT. One can observe that the performance curves of the wave rotor-topped engines are shifted to the lower right part of the diagram compared to the corresponding baseline gas turbines without wave rotor. Therefore the wave rotor integration, decreases baseline engine's $s f c$ and simultaneously increases its $w s$. 


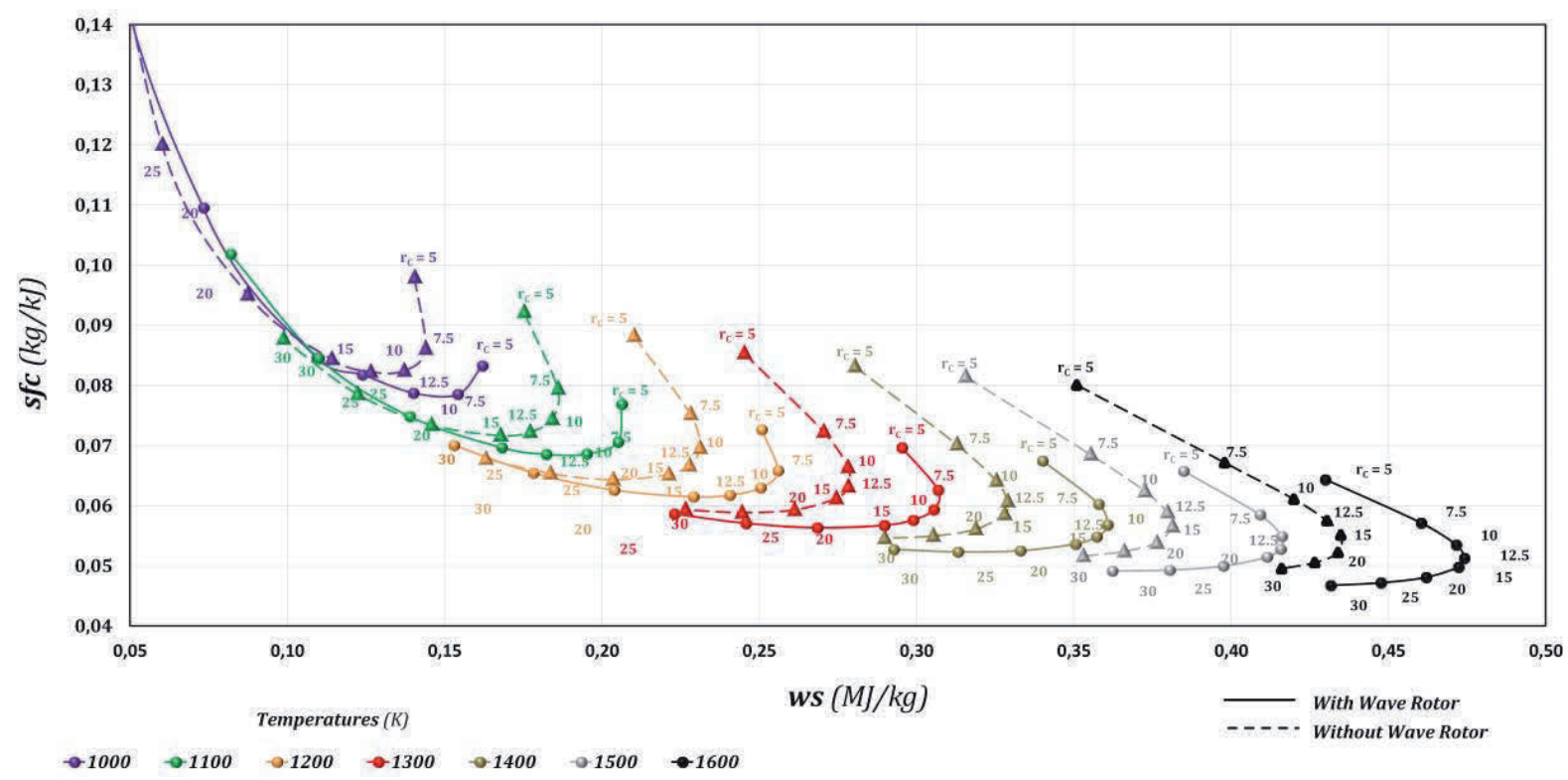

Figure 5: Specific fuel consumption against specific power for baseline and wave rotor-topped two-shaft gas turbines

Figures 4 and 5 indicate that low values of the compressor pressure ratio, $r_{c}$, are more favorable to the integration of a four port wave rotor to a gas turbine in terms of thermal efficiency, specific fuel consumption and specific power, especially at high values of TIT.

Figure 6 shows qualitatively the effect of integrating a four-port wave rotor on two-shaft engines. In this figure, a typical case with $P R=1.8$, $n_{C}=n_{E}=0.83$ for $T I T=1500 \mathrm{~K}$ is presented. In the same figure, the percentage increase in $w s$ (blue bars) and in $n_{t h}$ (grey bars) are illustrated.
A clear benefit in terms of $w s$ and $n_{t h}$ increase for all values of $r_{c}$ considered can be seen. More specifically, the prevalent increase in $n_{t h}$ reaches $19.3 \%$ and in ws reaches $18 \%$ for compressor ratio $r_{c}=5$. This increase decays as $r_{c}$ increases, ending up to a minimum value of $4.8 \%$ and $2.6 \%$ for $n_{t h}$ and $w s$ respectively, for $r_{c}=30$. This means that for all range of gas turbines there is a clear performance enhancement.

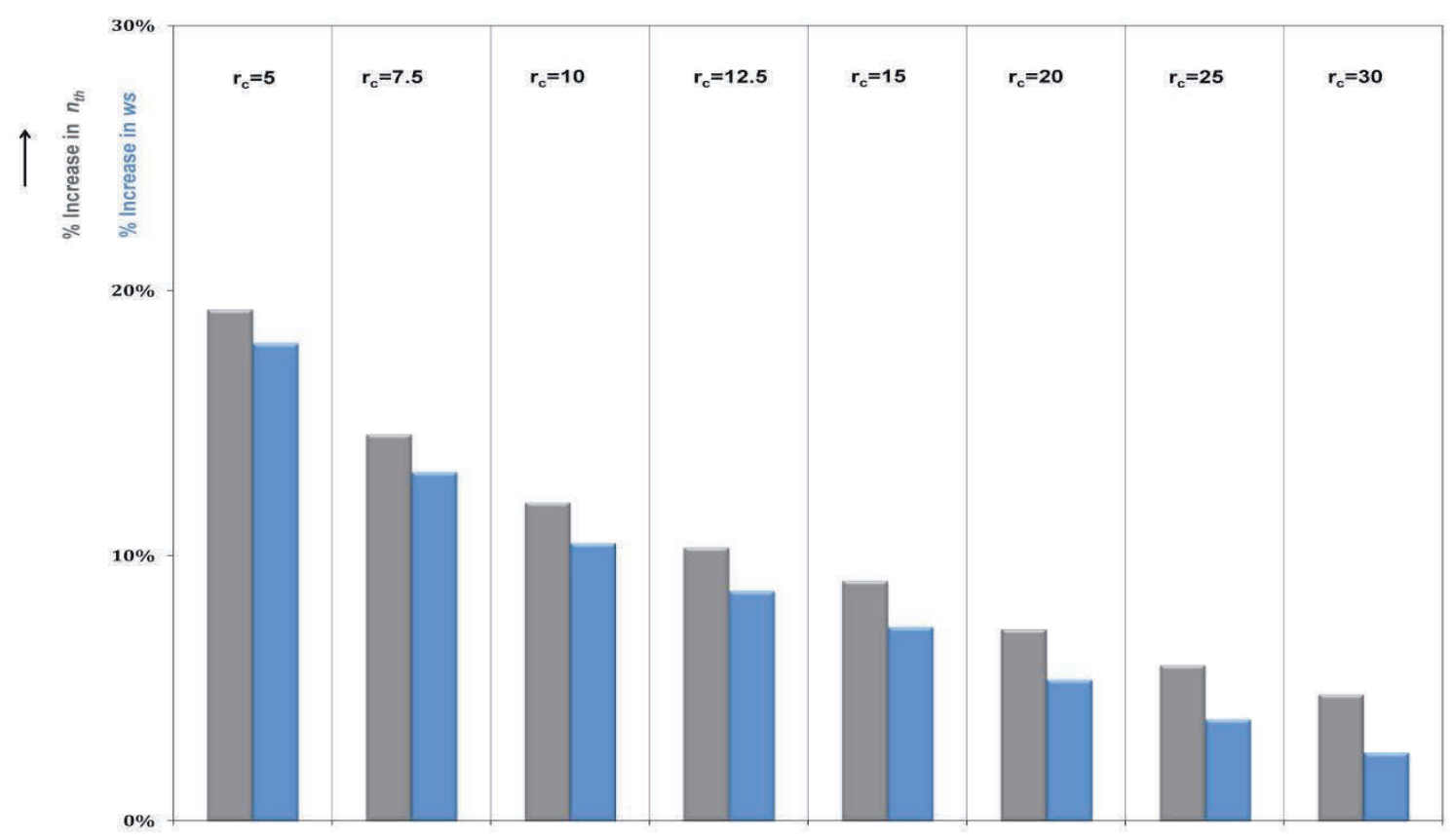

Figure 6: Increase in specific power (ws) (grey bars) and thermal efficiency ( $s f c$ ) (blue bars) for twoshaft gas turbines topped with four-port wave rotor with $\eta_{C}=\eta_{E}=0.83, P R=1.8$ for $T I T=1500 \mathrm{~K}$. 
Figure 7 shows qualitatively the effect on specific fuel consumption of integrating a four-port wave rotor on two-shaft engines. A typical case with $P R=1.8, n_{C}=n_{E}=0.83$ for $T I T=1500 \mathrm{~K}$ is presented. The major decrease in $s f c$ is $23.9 \%$ for $r_{c}=5$, descending to $5 \%$ for $r_{c}=30$.

Conclusively from figures 6 and 7, performance enhancement of two-shaft wave rotor-topped engines operating at design point conditions having $T I T=1500 \mathrm{~K}$ is maximized for low values of $r_{c}$. Referring to figures 4 and 5, we conclude that the higher the TIT (especially for low values of $r_{c}$ ) the more the benefits are for the engine's performance.

\subsection{Parameters influencing performance of two- shaft gas turbines}

Various studies carried out in the past, such as Welch et al. (1999), Fatsis and Ribaud (1999), Jones and Welch (1996), Povinelli et al. (2000) indicated that the main parameters influencing the performance of wave rotor topped two-shaft engines are:

(i) Wave rotor pressure ratio $(P R)$.

(ii) Pressure losses variation at the ducts connecting the wave rotor to compressor, combustion chamber and turbine $\left(\Delta P_{d u c t}\right)$, confirmed in previous studies by Fatsis and Ribaud (1999) and by Akbari and Mueller (2003).

Numerical studies done by Fatsis (2017) showed that the variation of the compression and expansion efficiencies inside the rotor $\left(\eta_{C}, \eta_{E}\right)$ influences the $s f c$ at values of TIT less than $1200 \mathrm{~K}$. As TIT increases, the influence of $\eta_{C}$ and $\eta_{E}$ variation is becoming negligible.

The influence of these parameters on the topped engine performance in combination with the typical baseline engine parameters shown in Table 1 , is examined setting a typical value of the Turbine Inlet Temperature $(T I T)$, namely $T I T=1500 \mathrm{~K}$, and applying compressor pressure ratios $r_{c}$ from 5 up to 25 or 30 .

\subsubsection{Effect of wave rotor pressure ratio} variation on performance of two-shaft gas turbines

Numerical and experimental studies carried out by Okamoto and Araki (2008), Jones and Welch (1996) and Povinelli et al. (2000), concluded that the operation of a four-port wave rotor is effective when its pressure ratio $P R$ attains the value of 1.8 .

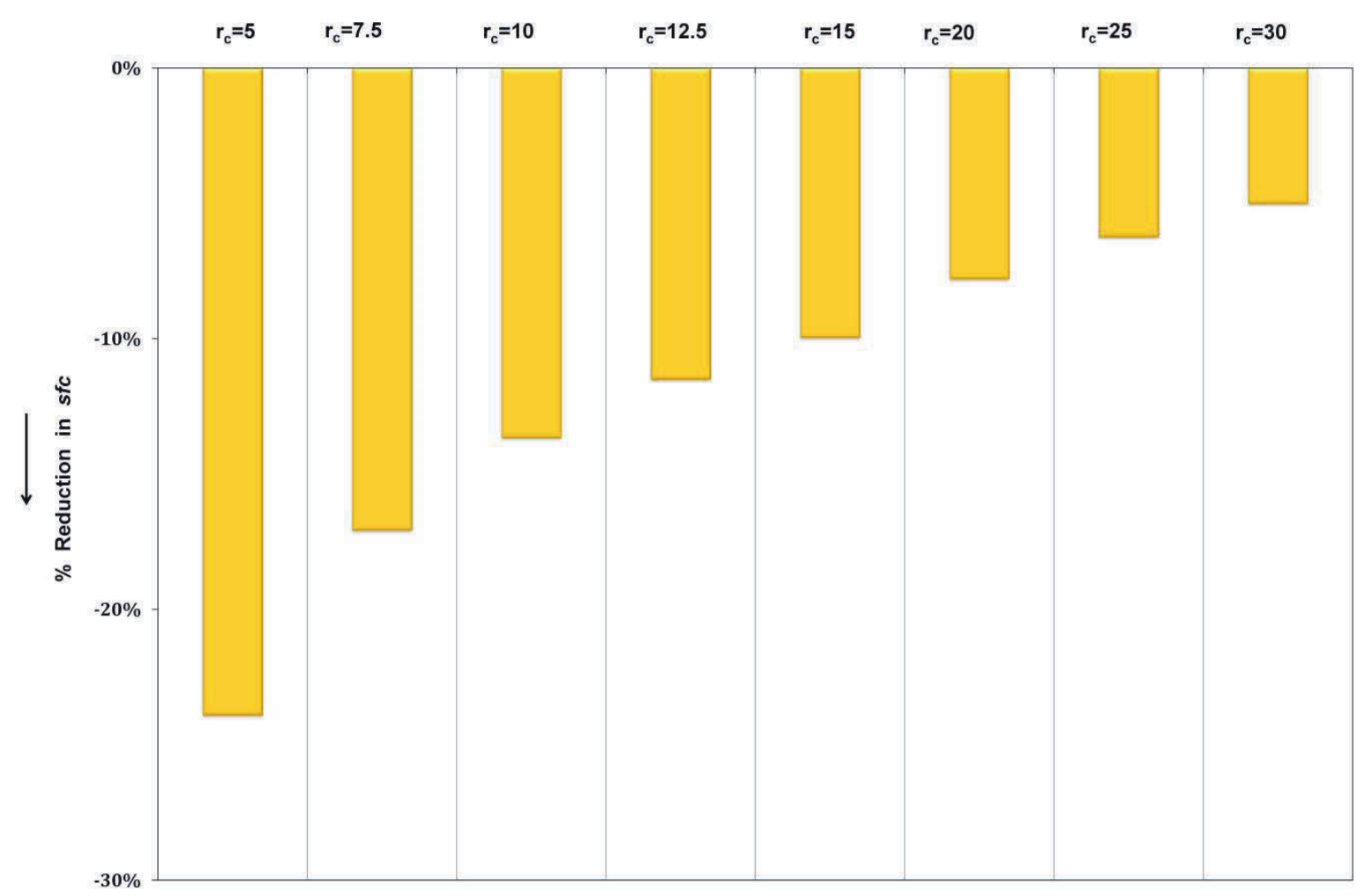

Figure 7: Reduction in specific fuel consumption $(s f c)$ for two-shaft gas turbines topped with four-port wave rotor with $\eta_{C}=\eta_{E}=0.83, P R=1.8$ for $T I T=1500 \mathrm{~K}$. 


\subsubsection{Effect of wave rotor pressure ratio} variation on performance of two-shaft gas turbines

Numerical and experimental studies carried out by Okamoto and Araki (2008), Jones and Welch (1996) and Povinelli et al. (2000), concluded that the operation of a four-port wave rotor is effective when its pressure ratio $P R$ attains the value of 1.8 .

Figure 8 presents the $s f c-w s$ distribution for twoshaft gas turbines with $T I T=1500 \mathrm{~K}$. The $P R$ variation has a slight effect on $s f c$ for low compressor pressure ratio $r_{c}$ values, but no effect on ws. For $r_{c}>10$, the gas turbine performance is independent of the wave rotor pressure ratio, $P R$. It is interesting to notice that for $r_{c}<10$, the case of $P R=1.4$ results to slightly lower $s f c$ and slightly higher $w s$ than the one corresponding to the $P R=2.2$ case. Therefore the influence of the wave rotor pressure ratio $P R$, has negligible effect on engine's performance for $T I T=1500 \mathrm{~K}$, when the rest parameters are kept unchanged.

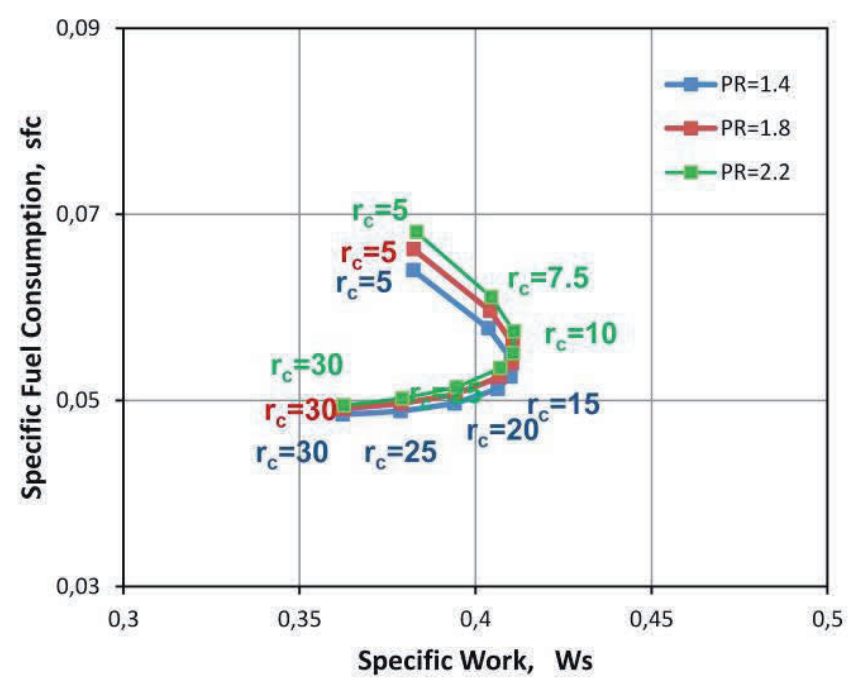

Figure 8: Performance of two-shaft gas turbines topped with four-port wave rotor with $\eta_{C}=\eta_{E}=0.83$, $T I T=1500 \mathrm{~K}$ and variation of $P R$ from 1.4 to 2.2

\subsubsection{Effect of leakage and pressure losses variation}

The effect of the pressure losses in ducts connecting the wave rotor to compressor, combustion chamber and turbine, as well as leakage losses at the extremities of the wave rotor $\left(\Delta P_{d u c t}\right)$, was analyzed by Welch et al. (1999) and by Slater and Welch (2005).

Figure 9 presents the $s f c-w s$ distribution for the case where $P R=1.8, T I T=1500 \mathrm{~K}, \eta_{C}=\eta_{E}=0.83$, for $\Delta P_{\text {duct }}=4 \%, 8 \%$. From this figure it can be seen that for $T I T=1500 \mathrm{~K}$, when ducting pressure losses
$\Delta P_{\text {duct }}$ are increased, $w s$ decreases with a slight increase in $s f c$. The effect of pressure losses is more apparent in low pressure ratios. The higher the pressure ratio, the less important is the effect of losses on engine's performance.

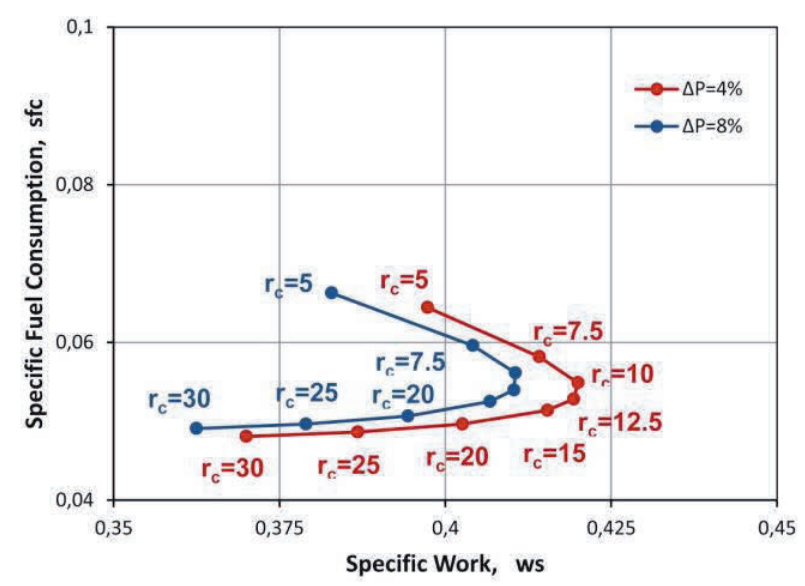

Figure 9: Performance of two-shaft gas turbines topped with four-port wave rotor with $P R=1.8, \eta_{C}$ $=\eta_{E}=0.83 T I T=1500 \mathrm{~K}$, ducting and leakage pressure losses $\Delta P_{\text {duct }}=4 \%, 8 \%$

\section{Wave Rotor two-Shaft Recuperated Gas Turbines analysis}

In industrial gas turbine industry, fuel economy can be achieved by introducing a recuperator in the baseline engine, Horlock, (2003). This device recovers waste energy from the gas turbine exhaust, preheating the air entering the combustion chamber, improving cycle efficiency and reducing fuel consumption, Shepard et al. (1994). The development of the Rolls Royce WR-21 engine for marine applications is based on this concept, Colin (2003).

Under this perspective, a four-port wave rotor can be introduced to the basic gas turbine - recuperator cycle, as Figure 10 illustrates.

The thermodynamic calculation of the recuperator is based on an iterative procedure. Initially the temperature of the "cold" exit 5.2 of the heat exchanger is assumed $\left(T_{05, h y p}\right)$. Then fuel mass flow through the combustion chamber is:

$\dot{m}_{f}=\dot{m} \frac{\left(C_{p h} T_{06}-C_{p c} T_{05, h y p}\right)}{n_{c c} F C V}$ 


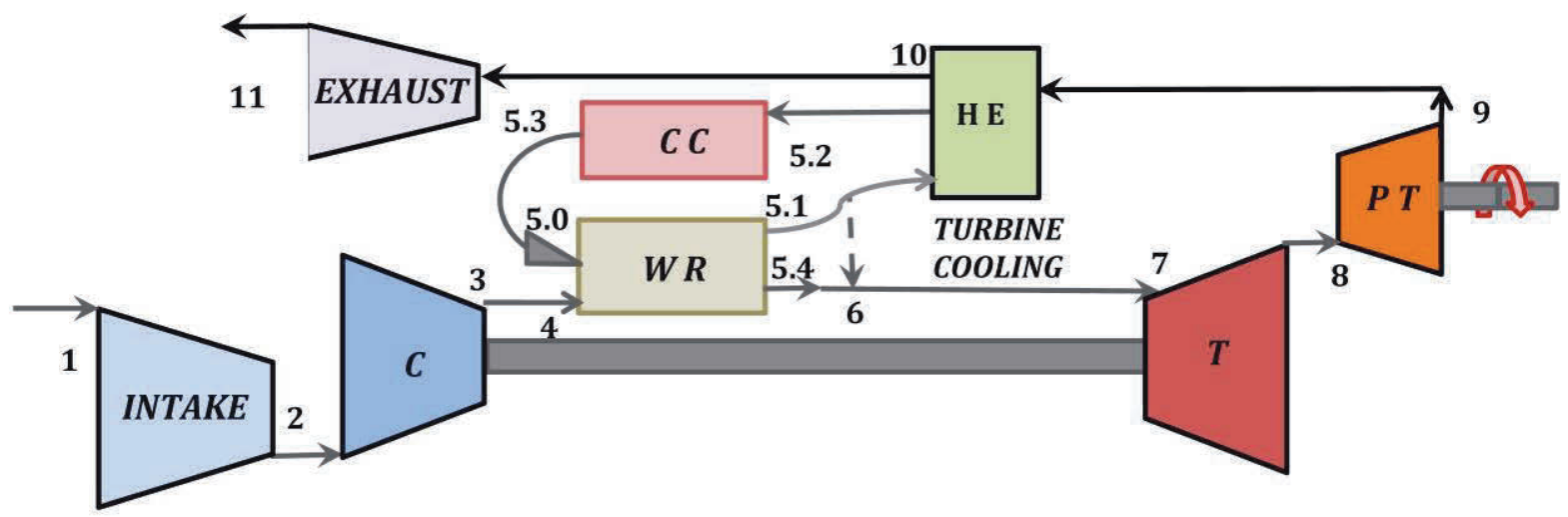

Figure 10: Two-shaft recuperated Gas Turbine configuration, C: gas turbine compressor, T: turbine, CC: combustion chamber, WR: wave rotor, CT: compressor turbine, PT: power turbine, HE: heat exchanger (recuperator)

The "hot" exit temperature of the recuperator $\left(T_{10}\right)$ is calculated as:

$$
T_{10}=T_{09}-n_{H E}\left(T_{09}-T_{5.1}\right)
$$

where $n_{H E}$ is the efficiency of the recuperator (its value lies between 0.84 and 0.92 ).

The updated value of the "cold" exit of the recuperator is calculated as:

$$
T_{05, \text { real }}=T_{5.2}=T_{5.1}+n_{H E}\left(T_{09}-T_{5.1}\right)
$$

If the quantity $\frac{\left|T_{05, \text { real }}-T_{05, \text { hyp }}\right|}{T_{05, \text { real }}}$ is less than a prescribed error (e.g. 0.001), then the calculation is converged, otherwise a new value $T_{05, \text { hyp }}=T_{05 \text {,real }}$ is assumed and a new iteration begins.

The pressure loss in the recuperator is expressed by means of the recuperator pressure loss $\Delta P_{H E \text {,loss }}$ that takes values between $1 \%$ and $4 \%$.

The performance map of two-shaft wave rotor recuperated engines with respect to the corresponding two-shaft baseline recuperated engines is shown in figure 11.

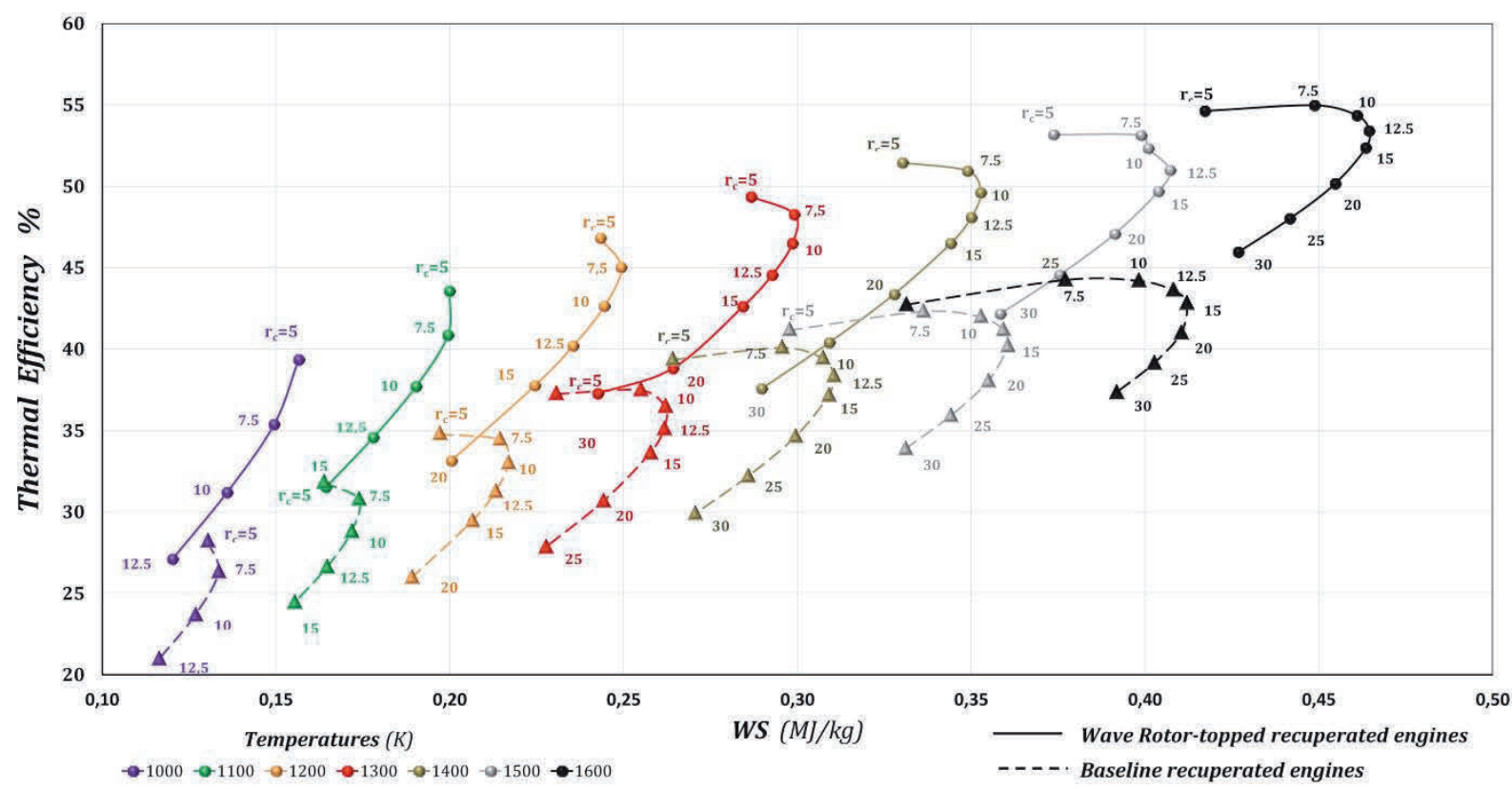

Figure 11: Thermal efficiency percentage against specific power for baseline and wave rotor-topped twoshaft recuperated gas turbines

As for the case of two-shaft wave rotor-topped engines without recuperator (figure 4), it can be observed that for low values of $r_{c}$, the integration of the wave rotor reduces significantly the engine's 
specific fuel consumption especially at high values of $T I T$.

At higher TIT values, the performance curves of the topped engines recover their expected fishhook shape.

Figure 12 shows qualitatively the effect of integrating a four-port wave rotor on two-shaft recuperated engines. A typical case with $P R=1.8$, $n_{C}=n_{C}=0.83$ for $T I T=1500 \mathrm{~K}$ is illustrated. In the same figure, the percentage increase in $n_{t h}$ is shown (the specific power, ws is not affected by the presence of the recuperator). From this figure, it can be seen that there is a benefit in terms of $n_{t h}$ increase for all values of $r_{c}$ considered. More specifically, the prevalent increase in $n_{t h}$ reaches $22.6 \%$ for compressor ratio $r_{c}=5$, whereas the minimum increase is never less than $19 \%$. This increase is kept almost constant as $r_{c}$ increases, even for engines with $r_{c}=25$ or 30 .
Figure 13 shows qualitatively the effect on specific fuel consumption of integrating a four-port wave rotor on two-shaft recuperated engines. A typical case with $P R=1.8, \quad n_{C}=n_{E}=0.83$ for $T I T=1500 \mathrm{~K}$ is presented. The decrease in $s f c$ goes down to $29.2 \%$ for $r_{c}=5$, and for $r_{c}=15$ is $23.7 \%$.

From figures 12 and 13, performance enhancement of two-shaft wave rotor-topped recuperated engines operating at design point conditions having $T I T=1500 \mathrm{~K}$ is maximized for low values of $r_{c}$, but there is a net benefit which is kept almost constant independent of the value of compressor pressure ratio. For the typical value of TIT examined, the net benefit in terms of thermal efficiency is more than $19 \%$ and the reduction in $s f c$ is close to $24 \%$ for all compressor pressure ratio values examined

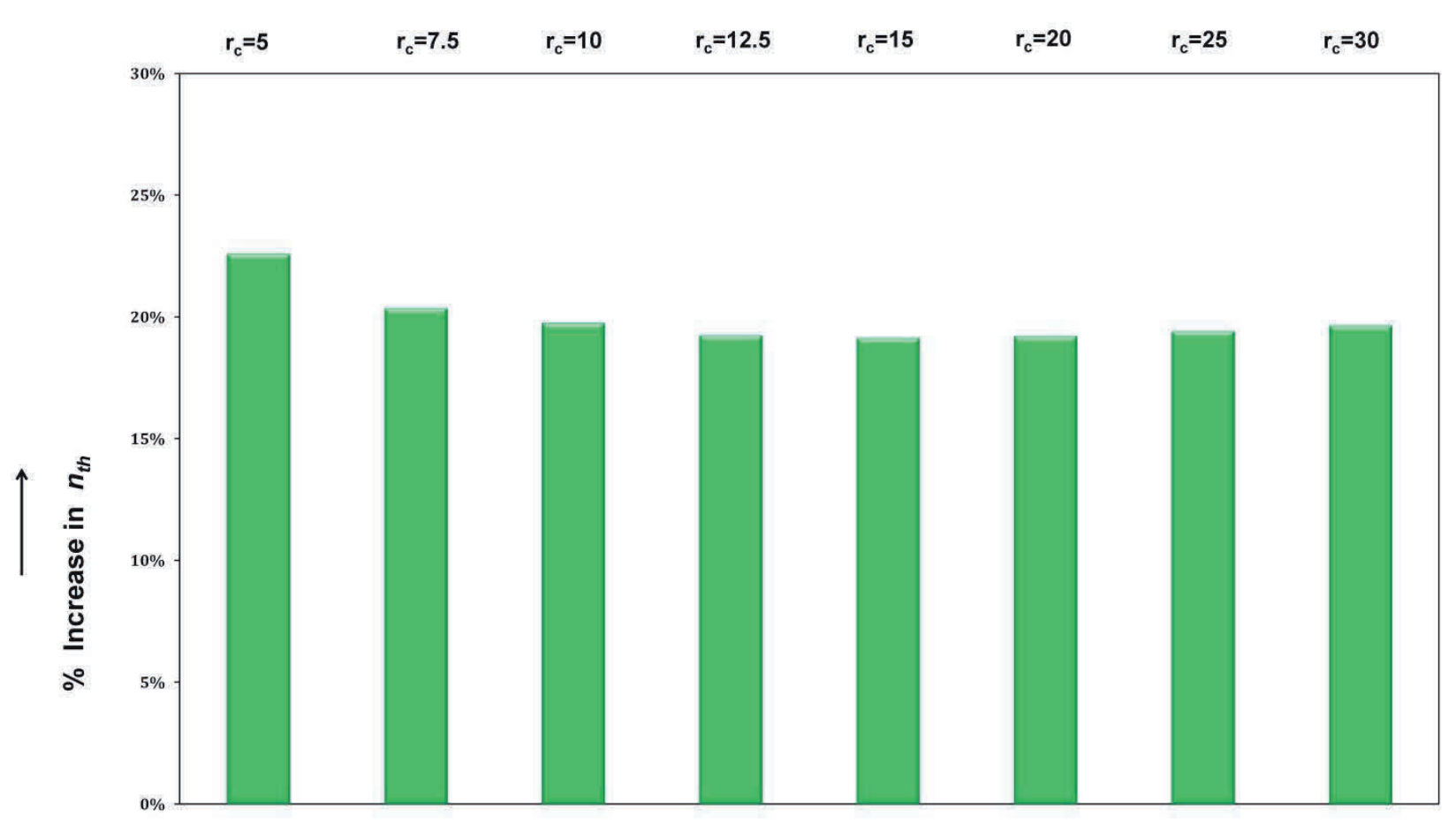

Figure 12: Increase in thermal efficiency $(s f c)$ for two-shaft recuperated gas turbines topped with fourport wave rotor with $\eta_{C}=\eta_{E}=0.83, P R=1.8$ for $T I T=1500 \mathrm{~K}$. 


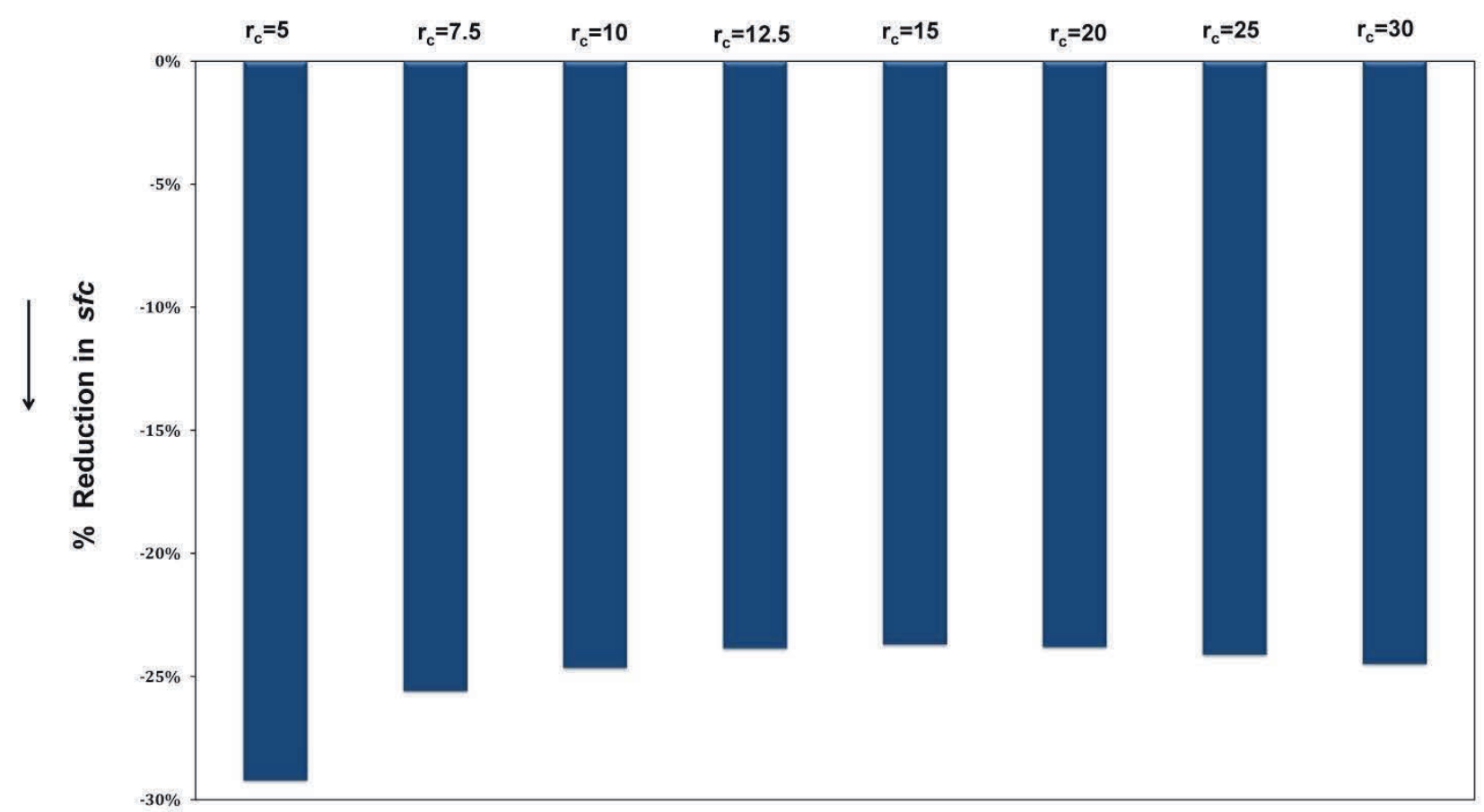

Figure 13: Reduction in specific fuel consumption $(s f c)$ for two-shaft recuperated gas turbines topped with four-port wave rotor with $\eta_{C}=\eta_{E}=0.83, P R=1.8$ for $T I T=1500 \mathrm{~K}$.

\section{Integration challenges}

The only case of engine built so far as a demonstrator is a Rolls-Royce Alison 250 turboprop two-shaft gas turbine with the integration of a four-port wave rotor (Welch et al., 1999). The original engine was modified to integrate the wave rotor and the associated ducting, keeping compressor, turbine and combustor the same. The rotor diameter and length were approximately equal to the tip diameter of the High Pressure Turbine. The wave rotor was mounted on a separate shaft between the turbine and combustor. The rotor spins coaxially with the gas turbine shaft at approximately one-third the speed of the gas generator spool through its operating range. As far as it concerns power plant gas turbines, typical wave rotor diameter and length are similar to those of the baseline engine. It was found to produce $11.4 \%$ more shaft power $(+20 \%$ specific power) with a $22 \%$ decrease in engine's $s f c$ at design point conditions. The greatest challenges are related to the design of the ducts connecting the combustion chamber to the turbine due to high temperatures. Snyder (1996) mentions that the estimated fabrication and program costs including three sets of hardware to be used in the testing phase was estimated in 1996 to 1,8 million U.S. \$. It must be noted that the price of a typical marine engine as the GE LM2500 exceeds 10 million US $\$$.

As for the case of industrial gas turbines, for marine gas turbines, the integration of a four-port wave rotor to an existing aero-derivative gas turbine is expected to increase the overall length of the engine as much as the turbine diameter without any increase in the maximum diameter of the engine.

A comparison between the wave rotor-topped twoshaft recuperated gas turbines and the wave rotortopped two-shaft gas turbines is illustrated in figure 14. One can observe that the thermal efficiency of wave rotor-topped two-shaft recuperated gas turbines is comparable to combined cycle efficiencies, surpassing $50 \%$ for values of $T I T \geq 1400 \mathrm{~K}$, whereas the specific power is almost the same between the wave rotor-topped recuperated double shaft and the wave rotor-topped engines. From this figure, it can be also seen that the integration of a wave rotor to a two shaft recuperated engine, favors engines with low compressor pressure ratios, $r_{c}$. For two shaft topped engines the highest thermal efficiencies are attained to intermediate values of $r_{c}$.

The expected merits of wave rotors for marine propulsion systems include:

- Increase in thermal efficiency of the baseline engine.

- Increase in specific power of the baseline engine.

- Reduction in specific fuel consumption of the baseline engine.

- Implementation to two shaft gas turbines and to recuperated two-shaft gas turbines configurations.

- Increment only in engine's length without significant changes in other dimensions and weight.

- Possibility of in-rotor constant volume combustion, (Elharis et al., 2010) replacing the 
conventional combustion chamber of gas turbines.

- Implementation to existing aero-derivative gas turbines without major changes to the basic components.

- Implementation to naval and commercial ships. Possible demerits are related to the fact that the wave rotor technology being novel and under development, needs investments to be conducted in:
- Design and manufacturing of necessary ducting to connect the wave rotor to existing components of the gas turbine.

- Cooling requirements of the ducts connecting combustion chamber exit to wave rotor "hot" inlet port.

- The fabrication of prototypes for experimental performance validation and design optimization of wave rotor-topped engines.

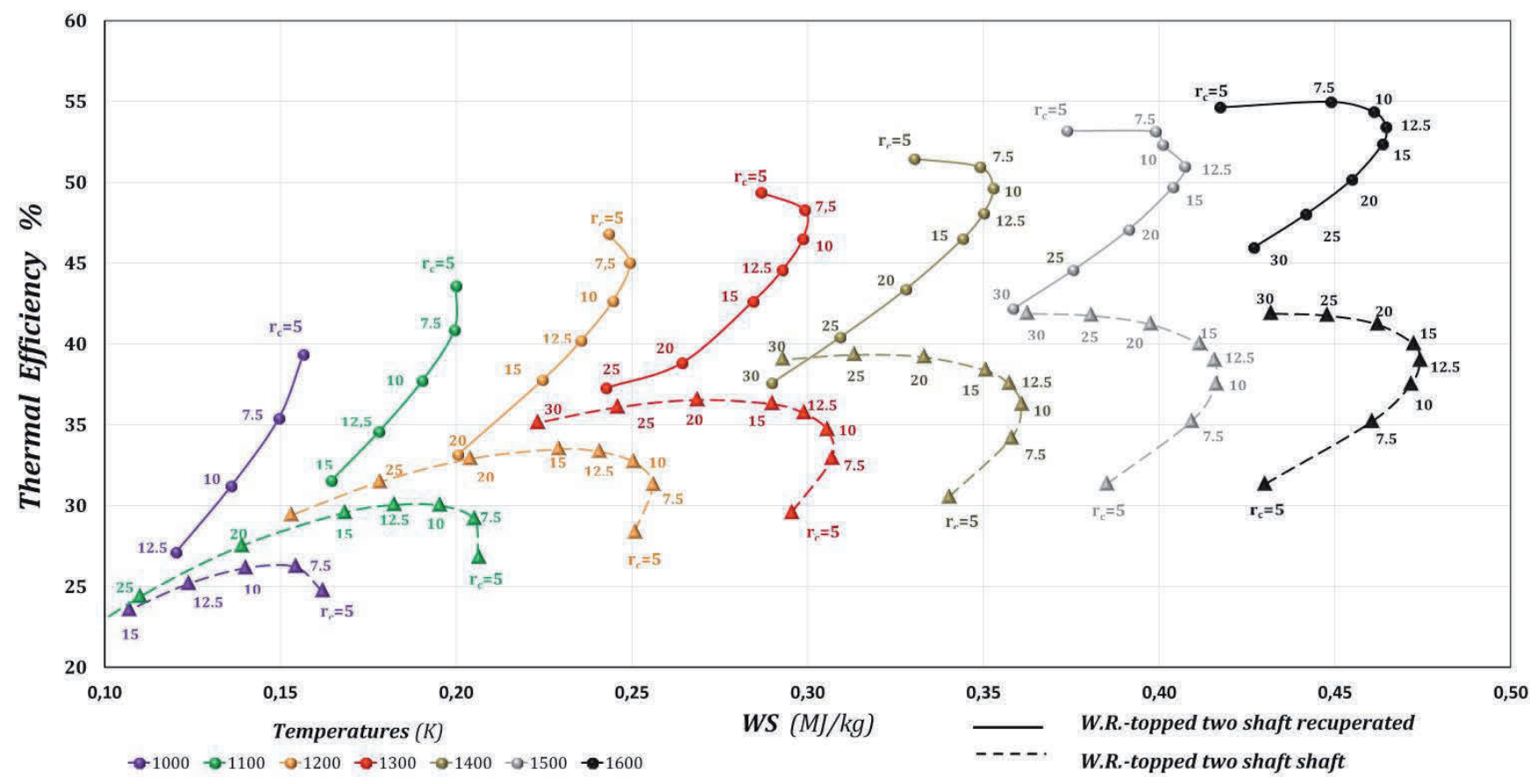

Figure 14: Comparison of performances between wave rotor-topped two-shaft recuperated (continuous lines) and wave rotor-topped two-shaft gas turbines (dashed lines)

\section{Conclusion}

In this article, performance assessment of two-shaft gas turbine engines topped with a four-port wave rotor as a prime mover for naval ships was performed. Integration of wave rotor technology in marine gas turbines can moderate the fuel consumption and increase the specific power of the engine. In marine gas turbines, the extra weight of the wave rotor-topped engine is negligible with respect to the weight of the naval ship and the extra dimensioning due to the wave rotor and the associated ducting do not impose major changes in the machine room. In the thermodynamic model developed, the compressor, gas turbine and compressor turbine of the baseline engine are kept unchanged to keep the wave rotor's integration cost low. Ambient pressure and temperature, thermodynamic constants for the air and hot gases, thermal efficiencies for compressor, compressor turbine and power turbine as well as compression and expansion efficiencies for the processes inside the wave rotor, are the input data required. Performance maps at design point illustrate the benefits of wave rotor-topped engines with respect to the corresponding baseline engines. Depending on the design requirements concerning specific power and specific fuel consumption, the topped engines maps help to select the most favourable engine and its precise operating conditions (compressor pressure ratio, turbine inlet temperature).

For two-shaft engines working at a given compressor pressure ratio, the higher the turbine inlet temperature is, the more the benefit gain of the wave rotor topped engine is attained in terms of thermal efficiency, specific fuel consumption and specific power. Assuming compression and expansion efficiencies inside the wave rotor, as well as ducting and leakage pressure losses specified by previous researchers, it was calculated for typical aero-derivative engines, such as the GE LM2500 series of the RR Olympus that that the increase in thermal efficiency remains higher than 
$8 \%$ and the increase in specific power remains higher than $6 \%$ at $T I T=1500 \mathrm{~K}$.

The parameters selected as important for the performance of the wave rotor and of the whole engine are: The wave rotor pressure ratio and the ducting and pressure losses associated with the wave rotor. Each of these parameters is varied around a mean value which is well-established in the literature and used by other researches in the past.

The influence of wave rotor pressure ratio $(P R)$ on specific fuel consumption is negligible for $r_{c}>10$ for $T I T=1500 \mathrm{~K}$. For all the cases examined no influence of $P R$ variation on specific power was observed.

Leakage and pressure losses are mainly influencing specific power, while specific fuel consumption remains almost unchanged. Results showed that when the pressure losses increase, specific fuel consumption also increases whereas specific power decreases, for all values of compressor pressure ratios examined. The effect of pressure losses is more apparent for low pressure ratios. The higher the pressure ratio, the minor the effect of losses on engine's performance will be.

For the case of wave rotor-topped recuperated gas turbine engines, the thermal efficiency increases by at least $19 \%$ and the specific fuel consumption decreases by at least $24 \%$ for all pressure ratios examined for $T I T=1500 \mathrm{~K}$ with respect to the baseline recuperated engines. Peak thermal efficiency can exceed $50 \%$ for $T I T \geq 1400 \mathrm{~K}$ and low values of the compressor pressure ratio.

Four-port wave rotors have the potential to enhance the performance of marine gas turbines, although there are challenges to be successfully surpassed.

\section{References}

Akbari P. and Mueller N. 2003. Performance investigation of small gas turbine engines topped with wave rotors", AIAA Paper 2003-4414.

Brady E.F.1988. Gas Turbine Systems for World Navy Ships. ASME Paper 88-GT-166.

Colin R. 2003. The WR-21 Intercooled Recuperated Gas Turbine Engine - Integration Into Future Warships, IGTC2003Tokyo OS-203. Proceedings of the International Gas Turbine Congress 2003 Tokyo.

Ebaid M. and Al-hamdan, Q. 2015. Thermodynamic Analysis of Different Configurations of Combined Cycle Power Plants. Mechanical Engineering Research. Vol. 5. No. 2.
Elharis, T.M., Wijeyakulasuriya, S.D. and Nalim, M.R. 2010. Wave Rotor Combustor Aerothermodynamic Design and Model Validation based on Initial Testing. AIAA Paper 2010-7041. 46th AIAA/ASME/SAE/ASEE Joint Propulsion Conference \& Exhibit. Nashville, USA.

Fatsis A., Ribaud Y. 1999. Thermodynamic analysis of gas turbines topped with wave rotors. Aerospace Science and Technology. Vol. 3. No.5.

Fatsis A. 2017. Parametric study on performance characteristics of wave rotor topped gas turbines. International Journal of Engineering Research \& Technology (IJERT). Vol. 6. Issue 6. pp. 449-456.

Fatsis A. 2018. Performance Enhancement of One and Two-Shaft Industrial Turboshaft Engines Topped with Wave Rotors. Int. Journal of Turbo and Jet Engines. Vol. 34. Issue, 2. pp. 137-147

Fatsis A. 2019. Design Point Analysis of TwoShaft Gas Turbine Engines topped by Four-Port Wave Rotors for Power Generation Systems. Ahead of print. Propulsion and Power Research.

Horlock J.H. 2003. Advanced Gas Turbine Cycles. Pergamon, Cambridge, United Kingdom.

Iancu F. and Müller N. 2005. Efficiency of Shock Wave Compression in a Microchannel. Journal of Microfluid and Nanofluid. Vol.2. No.1. pp. 50-63.

Jones S.M. and Welch G.E. 1996. Performance Benefits for Wave Rotor-topped Gas Turbine Engines. International Gas Turbine and Aeroengine Congress \& Exhibition, Birmingham, UK. Paper No. 96-GT-75.

Jonsson M., Bolland O., Bücker D. and Rost, M. 2005. Gas Turbine Cooling Model for evaluation of Novel Cycles. Proceedings of ECOS 2005, Trondheim, June 20-22, Norway.

Kayadelen H.K. and Üst, Y. 2013. Marine Gas Turbines, Proceedings of the $7^{\text {th }}$ International Advanced Technologies Symposium (IATS'13), 30 October - 1 November 2013, Istanbul, Turkey.

Moon S.W., Kwon H.W., Kim T.S., Kang D.W., Sohn J.L. 2018. A novel coolant cooling method for enhancing the performance of the gas turbine combined cycle. Energy. Vol. 160. pp. 625-634.

Okamoto, K., Nagashima, T. and Teramoto, S. 2004. Multi-Passage Gasdynamic Interactions in Wave Rotor. Proceedings of the $24^{\text {th }}$ International Congress of the Aeronautical Sciences. 
Okamoto K. and Araki M. 2008. Shock Wave Observation in Narrow Tubes for a Parametric Study on Micro Wave Rotor Design. Journal of Thermal Science. Vol.17. No.2. pp. 134-140.

Povinelli L.A., Welch G.E., Bakhle, M.A and Brown G.V. 2000. Potential Application of NASA Aerospace Technology to Ground-Based Power Systems. NASA TM 2000-209652.

Prasad K.B., Chand V.T., Kumar N., Ravindra K. and RAO V.N.B. 2016. Thermodynamic Analysis of Air Cooled Gas Turbine in Marine Applications, International Journal of Thermal Technologies. Vol. 6. No. 1. pp. 32-39.

Razak A.M.Y. 2007. Industrial Gas Turbines, Performance and Operability. Woodhead Publishing Limited, Cambridge, UK.

Royal Academy of Engineering. 2013. Future Ship Powering Options. Available at:

hiips://www.raeng.org.uk/publications/reports/fut ure-ship-powering-options
Shepard S.B., Bowen T.L., Chiprich J.M. 1994. Design and development of the WR-21 Intercooled Recuperated (ICR) Marine Gas Turbine. ASME Paper 94-GT-79.

Slater, J.W. and Welch G.E. 2005. Design of a Wave-Rotor Transition Duct. AIAA Paper 20055143.

Snyder P.H. 1996. Wave Rotor Demonstrator Engine Assessment. NASA CR 198496

Weber H.E. 1995. Shock Wave Engine Design. John Wiley and Sons, New York.

Welch G.E., Paxson D.E, Wilson J. and Snyder P.H. 1999. Wave-Rotor-Enhanced Gas Turbine Engine Demonstrator. NASA TM 209459.

Wilson J. and Paxson D. 1993. Jet Engine Performance Enhancement through use of a WaveRotor Topping Cycle, NASA TM 4486. 